\title{
Representasi Dakwah dalam Novel Ayat-Ayat Cinta 2 Karya Habiburrahman EI Shirazy
}

\author{
Kurnia Maulida $^{1}$, Chelsy Yesicha ${ }^{2}$ \\ Universitas Riau \\ e-mail: ${ }^{1}$ Kurniamaulida18@ gmail.com, ${ }^{2}$ chelsy.yesicha@lecturer.unri.ac.id
}

\begin{abstract}
Abstrak
Novel Habiburrahman El Shirazy yang berjudul Ayat-Ayat Cinta 2, terdapat bagian-bagian cerita yang menunjukkan adanya perubahan sikap tokoh yang awalnya membenci Islam menjadi bersikap positif terhadap Islam. Hal ini tentu saja karena adanya proses dakwah yang tidak hanya melalui lisan dan tulisan tetapi juga sikap dan perbuatan yang menunjukkan Islam yang baik. Tujuan penelitian ini adalah untuk mengetahui representasi dakwah dalam novel AyatAyat Cinta 2 dilihat berdasarkan alur cerita dan tokohnya, serta unsur ekstrinsik pengarang dalam merepresentasikan dakwah dalam novel. Penelitian ini menggunakan metode deskriptif dengan menggunakan analisis naratif Tzvetan Todorov dan Algirdas Greimas, sebagai pisau analisisnya. Selanjutnya diketahui bahwa sebagian besar dakwah yang ditunjukkan di dalam novel ini dilakukan oleh Fahri. Fahri melakukan semua jenis dakwah. Dakwah bisa dilakukan oleh siapa saja dan tokoh yang melakukan dakwah ini adalah orang yang tahu dan paham tentang apa yang seharusnya dilakukan lalu mengajak orang lain untuk melakukan hal yang sama. Unsur ekstrinsik pengarang dalam merepresentasikan dakwah dalam novel Ayat-Ayat Cinta 2 ini yaitu, biografi atau tepatnya latar belakang pendidikan, pengalaman pribadi, serta keadaan sosial yang dilihat dan dialami pengarang.
\end{abstract}

Kata kunci: Representasi, Analisis Naratif, Novel, Dakwah

\begin{abstract}
Habiburrahman El Shirazy's novel entitled Ayat-Ayat Cinta 2, there are parts of the story that show a change in the attitude of the character who initially hated Islam to be positive towards Islam. This is of course due to the da'wah process which is not only through oral and written but also attitudes and actions that show good Islam. The purpose of this study was to determine the representation of da'wah in the novel AyatAyat Cinta 2 seen based on the storyline and characters, as well as the author's extrinsic element in representing da'wah in the novel. This research uses descriptive method using narrative analysis of Tzvetan Todorov and Algirdas Greimas, as the analysis knife. Furthermore it is known that most of the da'wah shown in this novel was carried out by Fahri. Fahri does all kinds of da'wah. Da'wah can be done by anyone and the person who does this da'wah is someone who knows and understands what should be done then invites others to do the same. The author's extrinsic element in representing da'wah in the novel Ayat-Ayat Cinta 2, namely, biography or rather the educational background, personal experience, and social conditions seen and experienced by the author.
\end{abstract}

Keywords Representation, Narrative Analysis, Novel, Da'wah 


\section{PENDAHULUAN}

Islam merupakan agama Rahmatan lil 'Alamin yang dibawa oleh Nabi Muhammad SAW (Q.S. Al-Anbiya:107). Salah satu tugas yang harus dilakukan oleh manusia adalah untuk menegakkan amar ma'ruf nahi munkar dengan cara berdakwah. Dakwah Islam gencar dilakukan oleh Nabi dan para sahabat sejak dahulu dan masih terus berlanjut hingga sekarang oleh para ulama dan orang beriman lainnya. Orang yang menyampaikan dakwah disebut $d a$ 'i.

Pada era ini semua orang bisa dengan mudah menjadi da' $i$. Kita bisa menemukan banyak akun di sosial media baik milik pribadi maupun yang sengaja dibuat dengan tujuan untuk mengingatkan orang-orang tentang kebaikan dan mencegah mereka melakukan keburukan. Selain itu di akun pribadi pun banyak orang yang sadar dan berbaik hati untuk mengingatkan orang-orang di sekitarnya tentang kebaikan dan keburukan tersebut. Melalui sosial media juga, para ustad dan $d a ' i$ yang memiliki kemampuan ceramah yang baik menjadi viral dan diundang ke berbagai tempat. Ini tentu saja merupakan hal yang positif karena berdampak pada lebih luasnya jangkauan dakwah.

Dakwah bisa dilakukan dengan banyak cara, seperti melalui lisan (bi AlLisan), melalui tulisan (bi Al-Qalam), dan juga melalui perbuatan nyata berupa keteladanan (bi Al-Hal) (Amin, 2013:11). Dakwah yang banyak dilakukan sekarang ini, baik secara langsung maupun melalui sosial media adalah dakwah yang dilakukan secara verbal, yakni dakwah yang dilakukan melalui lisan dan tulisan, seperti ceramah di hadapan jamaah, ceramah yang disebarkan lewat sosial media, dan caption yang dituliskan di post-an. Sayangnya, kita masih jarang menemukan contoh nyata berupa keteladanan, padahal kalau kita menelaah kembali sejarah Nabi Muhammad SAW dalam menyampaikandakwahnya, beliau tidak hanya bertabligh, mengajar, atau mendidik dan membimbing,tetapi juga sebagaiuswatun hasanah(teladan yang baik). Dalam sebuah penelitian tentang dakwah yang dilakukan oleh Andri Hardiansyah, disebutkan bahwa dakwah dengan perbuatan ini bisa menjadi upaya untuk mengatasi kegagalan dakwah (2008:18). 
Selain sosial media, novel juga merupakan salah satu media yang banyak dimanfaatkan untuk melakukan dakwah melalui tulisan. Novel dapat dikategorikan sebagai media massa karena melalui novel seorang novelis yang bertindak sebagai komunikator dapat menyampaikan pesan-pesan yang ia inginkan dan diharapkan bisa memengaruhi pembaca.

Novel dengan genreislami merupakan salah satu yang sangat berkembang di Indonesia. Di Indonesia sendiri, karya sastra selain novel yang memakai genreini sudah berkembang sejak lama. MenurutAhmadun Yosi Herfanda, seorang yang konsisten mengikuti perkembangan sastra islami di Indonesia, novel bergenre islami muncul secara lebih semarak setelah Forum Lingkar Pena bergerak untuk mempopulerkannya kembali. Inilah yang kemudian melahirkan sosok sastrawan baru seperti Habiburrahman El Shirazy dengan karya Ayat Ayat Cinta, (http://nasional.republika.co.id).

Habiburrahman El Shirazy adalah seorang novelis yang konsisten menulis novel dengan genre islami. Beliau dinobatkan sebagai novelis No. 1 di Indonesia oleh INSANI UNDIP AWARD pada tahun 2008. Gaya penulisannya yang sarat akan unsur keislaman namun tidak mengurangi sisi romantis membuat banyak pembaca sangat menggemari karyanya.

Pada tahun 2015 Habiburrahman El Shirazy mulai menerbitkan karyanya Ayat-Ayat Cinta 2yang merupakan sequel dari novel fenomenalnya Ayat-Ayat Cintadalam bentuk cerita bersambung yang dimuat di harian Republika. Setelahnya pada 26 November 2015, bentuk novel dari cerita bersambung tersebut dirilis ke publik. Berdasarkan pernyataan Kepala Redaksi Republika, dalam waktu kurang dari satu bulan sejak diluncurkan, novel ini telah tembus 50 ribu eksemplar. Per Maret 2016, novel ini sudah mencapai cetakan yang ke-13. Fakta ini menjadikan buku Ayat-Ayat Cinta 2 ini masuk ke deretan novel Best Seller.

Menurut Habiburrahman El Shirazy sebagai pengarangnya, persamaan antara novel Ayat-Ayat Cinta dan Ayat-Ayat Cinta 2 adalah romansanya samasama menggetarkan hati, dan yang membedakannya adalah novel Ayat-Ayat Cinta mengisahkan perjuangan Fahri mendapatkan cinta sejati seorang wanita salehah yang menjadi istrinya, Aisha, sedangkan novel Ayat-Ayat Cinta 2 
mengisahkan perjuangan panjang Fahri menemukan kembali istrinya yang hilang selama bertahun-tahun di Palestina. Dalam novel Ayat-Ayat Cinta 2 Fahri diceritakan sebagai seorang pria bergelar doktor yang bekerja sebagai dosen pengganti di University of Edinburgh. Selain sebagai dosen, Fahri juga merupakan seorang pebisnis sukses di bidang boutique, mini mart dan restoran. Novel yang berlatar tempat di bumi Britania Raya tepatnya di Kota Edinburgh, ibukota Skotlandia ini, erat dengan masalah Islamophobia.

Kakak beradik tetangga Fahri di Stoneyhill Grove, Keira dan Jason, sangat membenci Fahri dan Islam karena mereka menganggap Islamlah yang menjadi penyebab meninggalnya Ayah mereka dalam peristiwa bom London. Mereka bersikap tidak ramah. Keira seringkali merusak mobil Fahri untuk melampiaskan rasa marah dan bencinya. Jason juga seringkali mencuri di mini mart milik Fahri. Namun Fahri sebagai seorang Muslim yang baik tidak pernah membalas perbuatan tetangganya tersebut. Ia malah dengan senang hati membantu kesulitan mereka hingga membiayai sekolah bola Jason dan les biola Keira. Sikap Fahri yang sangat baik ini malah membuat Jason tertarik ingin memeluk agama Islam. Pada halaman 184 dan 188 ditampilkan melalui narasi bagaimana Jason mulai melunak karena perlakuan yang dilakukan Fahri terhadap dirinya.

Tetangganya yang selama ini ia benci, ternyata pemilik minimarket dan restoran. Orang kaya dan baik hati. Semua kesalahannya yang berulang kali mencuri di minimarket itu dimaafkan. Bahkan ia diminta jadi sahabat.” (Shirazy, 2016:184)

Kini paling tidak, ia berpikiran tidak semua orang Islam seperti pengebom yang jahat itu. Buktinya, tetangganya yang muslim itu baik. Ia mengingat-ingat selama ini kepada tetangganya itu ia bersikap memusuhi dan menghina, tapi selama ini ia belum pernah melihat reaksi tetangganya yang marah kepadanya atau membalas hinaannya." (Shirazy, 2016:188)

Lalu pada halaman 462 terdapat dialog antara Fahri dan Jason dimana Jason mengungkapkan keinginannya untuk memeluk Islam. Jalan cerita ini sedikit banyak mirip dengan kisah Nabi dimana nabi tetap ikhlas dan tersenyum ketika ada orang yang meludahinya, lalu suatu ketika Nabi mendengar kabar orang 
tersebut sakit, Nabi tanpa ragu bersegera menjenguk dan mendoakan atas kesembuhannya. Orang itu pun akhirnya bersyahadat di hadapan Rasul karena malu dan juga terharu terhadap perlakuan yang dilakukan Nabi terhadapnya.

Tetangga depan rumah Fahri, Nenek Catarina yang beragama Yahudi juga seringkali dibantu olehnya. Walaupun Paman Hulusi, asistennya, seringkali menentang, namun Fahri tetap membantu dengan ikhlas karena ia merasa wajib membantu sesama manusia apalagi tetangga terlepas dari agama apapun yang dianut oleh orang tersebut. Ketika Nenek Catarina jatuh sakit, Fahrilah yang membawanya ke rumah sakit, Fahri juga yang membeli rumah Nenek Catarina yang dijual oleh anak tirinya yang kejam agar Nenek Catarina tetap bisa tinggal di rumah tersebut untuk menikmati masa tuanya. Dialog Nenek Catarina di halaman 244 menjelaskan betapa Nenek Catarina sangat berterima kasih atas kebaikan yang Fahri lakukan.

““'Kau bukan siapa-siapaku, tapi kau memperlakukan diriku seperti ibu kandungmu sendiri. Terima kasih, Fahri atas kebaikanmu. Kau seperti malaikat yang turun di Stoneyhill Grove" lirih Nenek Catarina dengan mata berkaca-kaca setelah diperiksa dokter bahwa tidak ada tulang yang patah." (Shirazy, 2016:244)

Sikap Fahri yang luar biasa ini membuat Nenek Catarina sangat tersentuh dan bertanya kepada Fahri apakah ia ingin Nenek Catarina memeluk Islam. Sesuai ajaran Islam yang tidak bersifat memaksa, Fahri tidak memaksakan Nenek Catarina untuk memeluk Islam, hingga akhirnya Nenek Catarina meninggal dalam keadaan tetap Yahudi karena ia telah berjanji pada mendiang suaminya untuk setia pada agamanya (Shirazy, 2016:478).

Dalam novel ini juga ada kisah tentang Sabina, seorang muslimah homeless yang meminta-minta di kota tersebut. Fahri serta beberapa muslim di Edinburgh menyusun rencana untuk membantu Sabina dan juga para homeless lain terutama yang muslim agar tidak lagi meminta-minta karena hal tersebut sangat dibenci oleh Nabi. Dalam kehidupan sehari-harinya diceritakan bahwa Fahri adalah Muslim yang sangat taat serta sabar dan bijak. Selain hal-hal seperti diatas, Fahri juga sering menasehati atau mengingatkan orang-orang di sekitarnya 
agar menjalankan hidup sesuai ajaran agama bahkan dalam hal kecil sekalipun seperti meminta untuk bersabar dan mengingatkan agar minum sambil duduk.

Berdasarkan penggalan cerita diatas, dapat dilihat bahwa dari awal cerita hingga akhir cerita terdapat perubahan sikap dan perilaku dari tokoh-tokoh yang awalnya membenci dan meremehkan Islam menjadi lebih menerima dan bersikap positif terhadap Islam dan pemeluknya. Peneliti ingin mengetahui dakwah yang seperti apa yang terjadi sepanjang cerita sehingga menyebabkan perubahan tersebut. Peneliti juga ingin melihat siapa saja tokoh-tokoh yang terlibat dan turut andil dalam melakukan dakwah ini dalam novel ini. Untuk itu peneliti memutuskan untuk meneliti bagaimana dakwah direpresentasikan dalam novel ini dengan melakukan analisis naratif. Analisis naratif adalah analisis yang digunakan untuk memahami teks narasi dengan melihat melalui unsur-unsur yang membentuknya. Analisis naratif yang digunakan adalah analisis naratif model Tzvetan Todorov untuk melihat berdasarkan plot atau alur ceritanya dan analisis model Algirdas Greimas untuk melihat berdasarkan hubungan antar tokohnya. Selain itu peneliti juga tertarik untuk melihat bagaimana unsur ekstrinsik pengarang dalam merepresentasikan dakwah dalam novel Ayat-Ayat Cinta 2 ini.

Keputusan untuk melakukan penelitian ini juga didukung fakta tentang dakwah yang terjadi di masa sekarang yang hanya banyak dilakukan melalui lisan dan tulisan saja dan pernyataan dari Habiburrahman El Shirazy yang dilansir oleh republika.co.id, dalam bedah novel Ayat-Ayat Cinta 2 yang diadakan di Amerika Serikat pada tanggal 26 Desember 2015, bahwa Ayat Ayat Cinta 2 memotivasi kaum muda Muslim untuk berani menghadapi tantangan dakwah di era global, dengan kekuatan ilmu, iman, dan akhlaqul karimah. Beliau juga menyatakan bahwa "Di Ayat-Ayat Cinta 2, tokoh utama novel tersebut, yakni Fahri menunjukkan cara dakwah yang indah, penuh cinta dan cerdas," (http://nasional.republika.co.id).

Penelitian ini merupakan penelitian deskriptif kualitatif dengan menggunakan paradigma konstruktivis. Penelitian ini menggunakan analisis naratif Tzvetan Todorov dan Algirdas Greimas untuk melihat representasi dakwah dalam Novel Ayat-Ayat Cinta 2 melalui alur cerita dan hubungan antar tokohnya. 
Penelitian ini juga melihat unsur ekstrinsik pengarang dalam merepresentasikan dakwah dalam novel ini.

Subjek dalam novel ini adalah novel Ayat-Ayat Cinta 2 karya Habiburrahman El Shirazy cetakan ke-13 tahun 2016 dengan jumlah halaman sebanyak 698. Objek yang diteliti dalam penelitian ini adalah representasi dakwah dalam novel Ayat-Ayat Cinta 2. Bagian cerita yang diteliti adalah semua narasi dan dialog yang menunjukkan perilaku dakwah baik melalui lisan (bi Al-Lisan), tulisan (bi Al-Qalam), maupun perbuatan nyata (bi Al-Hal).

Teknik pengumpulan data dalam penelitian ini menggunakan studi dokumentasi, studi pustaka, dan wawancara.

\section{PEMBAHASAN}

Penelitian yang dilakukan ini merupakan penelitian deskriptif kualitatif dengan menggunakan kajian analisis naratif untuk melihat representasi dakwah dalam novel Ayat-Ayat Cinta 2 karya Habiburrahaman El Shirazy. Selain itu peneliti juga meneliti unsur ekstrinsik pengarang dalam merepresentasikan dakwah dalam novel Ayat-Ayat Cinta 2 ini. Pada bagian ini peneliti akan memaparkan hasil penelitian yang didapatkan yang akan dijelaskan sesuai dengan identifikasi masalah.

Teori yang digunakan dalam penelitian ini yaitu analisis naratif Tzvetan Todorov untuk melihat representasi berdasarkan alur cerita awal, tengah, dan akhir. Pada alur cerita tengah peneliti membagi alur ceritanya berdasarkan modifikasi oleh Gillespie. Selanjutnya teori yang digunakan adalah analisis naratif Algirdas Greimas untuk melihat representasi berdasarkan hubungan antar tokoh dalam novel ini. Sedangkan untuk menjawab identifikasi masalah yang ketiga tentang unsur ekstrinsik pengarang dalam merepresentasikan dakwah dalam novel, peneliti telah melakukan wawancara dengan Habiburrahman El Shirazy melalui pesan teks. Dakwah dalam novel ini ditunjukkan melalui dialog antar tokoh dan juga narasi paparan kejadian yang dialami oleh para tokoh.

Novel ini terdiri dari 42 bab dengan total halaman sebanyak 698. Walaupun cerita utama novel ini adalah tentang perjuangan Fahri untuk 
menemukan istrinya yang hilang, namun dalam jalan ceritanya terdapat banyak masalah-masalah lain yang dihadapi Fahri dan harus diselesaikan.

\section{Analisis Naratif Tzvetan Todorov pada Alur Cerita}

Alur cerita dalam novel ini dianalisis dengan menggunakan analisis Tzvetan Todorov yang menyatakan bahwa setiap cerita memiliki awal, tengah, dan akhir cerita. Pada bagian tengah cerita digunakan modifikasi oleh Gillespie yang membaginya menjadi 3 tahap yakni gangguan (kekacauan), komplikasi (kekacauan makin besar), dan klimaks (konflik memuncak).

Dakwah adalah suatu aktivitas yang dilakukan secara sadar dalam rangka menyampaikan pesan-pesan agama Islam kepada orang lain agar mereka menerima ajaran Islam tersebut dan menjalankannya dengan baik dalam kehidupan individual maupun bermasyarakat untuk mencapai kebahagiaan manusia baik di dunia maupun di akhirat, dengan menggunakan media dan caracara tertentu.Dakwah juga dapat diartikan sebagai proses penyampaian ajaran agama Islam kepada umat manusia. Secara umum dakwah dapat dibagi menjadi tiga macam, yakni dakwahbi Al-Lisan, dakwah bi Al-Hal, dan dakwah bi AlQalam (Amin, 2013:11).

Dakwah bi Al-Lisan, yaitu dakwah yang dilaksanakan melalui lisan, yang dilakukan antara lain dengan ceramah-ceramah, khutbah, diskusi, nasihat, dan lain-lain.Berdasarkan surah An-Nahl ayat 125, Allah juga memerintahkan untuk berdakwah dengan lisan ini yaitu dengan cara memberikan nasihat yang baik (mau'idhah hasanah) dan juga berdiskusi dengan cara yang baik. Dakwah bi AlHal, yakni dakwah dengan perbuatan nyata yang meliputi keteladanan dan hasilnya dapat dirasakan oleh masyarakat. Selain itu dakwah bi al-hal ini juga disebutkan Allah dalam surah An-Nahl ayat 125 yakni dengan cara hikmah, dakwah bi al-hikmah yang dilakukan oleh Rasulullah yaitu memberikan teladan yang terbaik dalam sikap dan perilaku, dengan selalu sopan santun kepada siapapun yang kemudian diistilahkan dengan akhlaqul karimah. Sehingga ketika seorang Muslim juga menunjukkan sikap dan perbuatan yang baik (akhlaqul karimah) maka ia menerapkan metode dakwah yang dicontohkan oleh Nabi 
Muhammad SAW. Selain akhlaqul karimahyang ditunjukkan kepada orang non Muslim sehingga mengubah pandangan mereka, dakwah bi Al-Hal juga dilakukan kepada sesama Muslim, seperti membantu saudara Muslim yang kurang mampu sehingga mereka tidak melakukan perbuatan buruk yang merusak citra Islam. Dakwah bi Al-Qalam yakni dakwah melalui tulisan yang dilakukan dengan keahlian menulis. Tulisan yang dapat dikategorikan sebagai dakwah bi AlQalamdiantaranya artikel keislaman, tanya jawab hukum Islam, rubrik dakwah, rubrik pendidikan agama, kolom keislaman, cerita religius, cerpen religius, puisi keagamaan, publikasi khurbah, pamflet keislaman, dan buku-buku. Dalam novel ini dakwah bi Al-Qalam yang ditunjukkan adalah dengan menulis riset dan artikel keislaman.

Alur cerita dan kategori dakwah yang dilakukan dalam novel ini dapat diklasifikasi menjadi sebagai berikut:

Tabel 1. Alur Cerita dan Kategori Dakwah

\begin{tabular}{|c|c|c|c|}
\hline Kategori Alur & $\mathrm{Bab}$ & Deskripsi & Kategori Dakwah \\
\hline \multirow[t]{2}{*}{ Awal cerita } & Bab 1 & $\begin{array}{l}\text { - Fahri mengajarkan amanah di kelas } \\
\text { filologi } \\
\text { - Fahri memberi contoh amanah } \\
\text { - Fahri mengerjakan sholat di awal } \\
\text { waktu } \\
\text { - Fahri mengajak sholat } \\
\text { - Fahri menjawab pertanyaan seputar } \\
\text { Islam } \\
\text { - Fahri melakukan kajian terhadap } \\
\text { wasiat ulama } \\
\text { - Fahri mengajak Paman Hulusi } \\
\text { sholat berjamaah } \\
\text { - Fahri menawarkan tumpangan } \\
\text { kepada tetangganya }\end{array}$ & $\begin{array}{l}\text { - bi Al Lisan } \\
\text { - bi Al Hal } \\
\text { - bi Al Hal } \\
\text { - bi Al Lisan } \\
\text { - bi Al Lisan } \\
\text { - bi Al Qalam } \\
\text { - bi Al Lisan } \\
\text { - bi Al Hal }\end{array}$ \\
\hline & Bab 2 & $\begin{array}{l}\text { - Fahri melakukan riset pada karya } \\
\text { ulama } \\
\text { - Fahri mengajak Paman Hulusi }\end{array}$ & $\begin{array}{l}\text { - bi Al Qalam } \\
\text { - bi Al Lisan }\end{array}$ \\
\hline
\end{tabular}


Kurnia, Chelsy, Representasi Dakwah dalam Novel Ayat-ayat Cinta...

\begin{tabular}{|c|c|c|c|}
\hline & & $\begin{array}{l}\text { membantu tetangga } \\
\text { - Fahri mengingatkan Paman Hulusi } \\
\text { - Fahri berusaha menjaga hubungan } \\
\text { baik dengan tetangga } \\
\text { - Fahri sabar terhadap perlakuan } \\
\text { jahil } \\
\text { - Fahri menasihati Paman Hulusi }\end{array}$ & $\begin{array}{l}\text { - bi Al Lisan } \\
\text { - bi Al Hal } \\
\text { - bi Al Hal } \\
\text { - bi Al Lisan }\end{array}$ \\
\hline & Bab 3 & $\begin{array}{l}\text { - Fahri memperbaiki bacaan imam } \\
\text { yang salah } \\
\text { - Fahri memberikan pengertian pada } \\
\text { seorang jamaah } \\
\text { - Fahri menasihati Paman Hulusi }\end{array}$ & $\begin{array}{l}\text { - bi Al Lisan } \\
\text { - bi Al Lisan } \\
\text { - bi Al Lisan }\end{array}$ \\
\hline & Bab 4 & $\begin{array}{l}\text { - Fahri, Heba, Juu suh, dan Ashley } \\
\text { berdiskusi tentang ajaran Islam }\end{array}$ & - bi Al Lisan \\
\hline \multicolumn{4}{|l|}{ Tengah cerita } \\
\hline \multirow{5}{*}{$\begin{array}{l}\text { Gangguan } \\
\text { (kekacauan) }\end{array}$} & Bab 5 & - Fahri membiayai Misbah & - bi Al Hal \\
\hline & Bab 6 & $\begin{array}{l}\text { - Fahri membangunkan Misbah } \\
\text { untuk sholat bersama } \\
\text { - Fahri membela pengemis yang } \\
\text { dihujat }\end{array}$ & $\begin{array}{l}\text { - bi Al Lisan } \\
\text { - bi Al Lisan }\end{array}$ \\
\hline & Bab 7 & $\begin{array}{l}\text { - Fahri mengantar Nenek Catarina ke } \\
\text { sinagog }\end{array}$ & - bi Al Hal \\
\hline & Bab 8 & $\begin{array}{l}\text { - Fahri menasihati Paman Hulusi } \\
\text { tentang berbuat baik tanpa pandang } \\
\text { bulu } \\
\text { - Heba menyampaikan satu ayat } \\
\text { pada temannya }\end{array}$ & $\begin{array}{l}\text { - bi Al Lisan } \\
\text { - bi Al Lisan }\end{array}$ \\
\hline & Bab 9 & $\begin{array}{l}\text { - Fahri bersabar atas perlakuan Jason } \\
\text { - Fahri mengantar Nenek Catarina ke } \\
\text { rumah } \\
\text { - Fahri menjenguk Profesor } \\
\text { Charlotte } \\
\text { - Fahri mengajarkan Paman Hulusi }\end{array}$ & $\begin{array}{l}\text { - bi Al Hal } \\
\text { - bi Al Hal } \\
\text { - bi Al Hal } \\
\text { - bi Al Lisan }\end{array}$ \\
\hline
\end{tabular}


Kurnia, Chelsy, Representasi Dakwah dalam Novel Ayat-ayat Cinta...

\begin{tabular}{|c|c|c|c|}
\hline & & $\begin{array}{l}\text { tentang sifat lemah lembut } \\
\text { - Fahri mengantar makanan ke } \\
\text { rumah Nenek Catarina }\end{array}$ & - bi Al Hal \\
\hline & Bab 10 & $\begin{array}{l}\text { - Fahri membangunkan Paman } \\
\text { Hulusi untuk sholat dhuha } \\
\text { - Misbah menasihati Fahri dan } \\
\text { dirinya sendiri } \\
\text { - Fahri mengingatkan Ju Se untuk } \\
\text { berpakaian sopan } \\
\text { - Fahri memberi tumpangan pada } \\
\text { Nyonya Janet } \\
\text { - Paman Hulusi menasihati Nyonya } \\
\text { Janet } \\
\text { - Fahri menasihai Paman Hulusi } \\
\text { untuk bersabar menghadapi Jason }\end{array}$ & $\begin{array}{l}\text { - bi Al Lisan } \\
\text { - bi Al Lisan } \\
\text { - bi Al Lisan } \\
\text { - bi Al Lisan } \\
\text { - bi Al Lisan } \\
\text { - bi Al Lisan }\end{array}$ \\
\hline & Bab 11 & $\begin{array}{l}\text { - Fahri menasihati Paman Hulusi } \\
\text { untuk bersabar menghadapi Keira } \\
\text { - Fahri memutuskan untuk mengurus } \\
\text { masalah vandalisme Keira dengan } \\
\text { damai } \\
\text { - Fahri dan Misbah berdiskusi } \\
\text { tentang hukum menjual barang } \\
\text { haram }\end{array}$ & $\begin{array}{l}\text { - bi Al Lisan } \\
\text { - bi Al Hal }\end{array}$ \\
\hline Komplikasi & Bab 12 & $\begin{array}{l}\text { - Fahri menangani masalah } \\
\text { pencurian Jason dengan cara halus } \\
\text { - Fahri membuat rencana untuk } \\
\text { menolong homeless bersama Tuan } \\
\text { Taher, Heba dan Misbah }\end{array}$ & $\begin{array}{l}\text { - bi Al Hal } \\
\text { - bi Al Hal }\end{array}$ \\
\hline makin besar) & Bab 13 & $\begin{array}{l}\text { - Fahri menghibur Nenek Catarina } \\
\text { yang sedih } \\
\text { - Fahri menolong dan mengajak } \\
\text { Sabina tinggal di rumahnya }\end{array}$ & $\begin{array}{l}\text { - bi Al Hal } \\
\text { - bi Al Hal }\end{array}$ \\
\hline & Bab 14 & - Fahri memberi masukan pada Tuan & - bi Al Lisan \\
\hline
\end{tabular}


Kurnia, Chelsy, Representasi Dakwah dalam Novel Ayat-ayat Cinta...

\begin{tabular}{|c|c|c|}
\hline & $\begin{array}{l}\text { Taher tentang menolak lamaran } \\
\text { - Fahri menyelamatkan Keira } \\
\text { - Fahri mengingatkan Paman Hulusi } \\
\text { untuk minum sambil duduk }\end{array}$ & $\begin{array}{l}\text { - bi Al Hal } \\
\text { - bi Al Lisan }\end{array}$ \\
\hline Bab 15 & $\begin{array}{l}\text { - Fahri memberi penjelasan pada } \\
\text { Paman Hulusi tentang cara ia } \\
\text { menolong Sabina, Keira dan Nenek } \\
\text { Catarina } \\
\text { - Fahri mengingatkan Sabina tentang } \\
\text { perilaku meminta-minta }\end{array}$ & $\begin{array}{l}\text { - bi Al Lisan } \\
\text { - bi Al Lisan }\end{array}$ \\
\hline Bab 16 & $\begin{array}{l}\text { - Fahri menyelamatkan Nenek } \\
\text { Catarina yang diusir oleh anaknya }\end{array}$ & - bi Al Hal \\
\hline Bab 17 & $\begin{array}{l}\text { - Fahri membiayai les biola Keira } \\
\text { - Fahri memeriksa paper ilmiah Ju } \\
\text { Se untuk dikirim ke Journal of } \\
\text { Arabic and Islamic Studies } \\
\text { - Fahri mengingatkan Paman Hulusi } \\
\text { untuk berbicara dengan lembut } \\
\text { - Sabina menawarkan Nenek } \\
\text { Catarina untuk dibuatkan sup } \\
\text { - Fahri menasihati Paman Hulusi } \\
\text { untuk bersabar }\end{array}$ & $\begin{array}{l}\text { - bi Al Lisan } \\
\text { - bi Al Hal } \\
\text { - bi Al Lisan }\end{array}$ \\
\hline Bab 18 & $\begin{array}{l}\text { - Fahri bersabar mendengar ejekan } \\
\text { umat Yahudi tentang Islam } \\
\text { - Fahri menawarkan untuk } \\
\text { berdiskusi pada orang Yahudi } \\
\text { - Syaikh Utsman menasihati Fahri } \\
\text { tentang menolak lamaran }\end{array}$ & $\begin{array}{l}\text { - bi Al Hal } \\
\text { - bi Al Lisan } \\
\text { - bi Al Lisan }\end{array}$ \\
\hline Bab 19 & $\begin{array}{l}\text { - Paman Hulusi mengingatkan Fahri } \\
\text { tentang kelebihan menikah } \\
\text { - Fahri mengajak Paman Hulusi } \\
\text { untuk sholat berjamaah } \\
\text { - Fahri membeli rumah Nenek }\end{array}$ & $\begin{array}{l}\text { - bi Al Lisan } \\
\text { - bi Al Lisan } \\
\text { - bi Al Hal }\end{array}$ \\
\hline
\end{tabular}




\begin{tabular}{|c|c|c|c|}
\hline & & $\begin{array}{l}\text { Catarina untuk diberikan padanya } \\
\text { - Fahri, Sabina, Paman Hulusi } \\
\text { membantu Nenek Catarina pindah } \\
\text { ke rumahnya }\end{array}$ & - bi Al Hal \\
\hline & Bab 20 & $\begin{array}{l}\text { - Fahri menawarkan sarapan dan } \\
\text { menawarkan mengantar ke sinagog } \\
\text { pada Nenek Catarina } \\
\text { - Fahri menjelaskan arti basmalah } \\
\text { pada Nenek Catarina }\end{array}$ & $\begin{array}{l}\text { - bi Al Hal } \\
\text { - bi Al Lisan }\end{array}$ \\
\hline & Bab 22 & $\begin{array}{l}\text { - Fahri mengingatkan untuk saling } \\
\text { menolong sesama } \\
\text { - Fahri menjelaskan tentang shalat } \\
\text { jama, }\end{array}$ & $\begin{array}{l}\text { - bi Al Lisan } \\
\text { - bi Al Lisan }\end{array}$ \\
\hline & Bab 23 & $\begin{array}{l}\text { - Paman Eqbal membangunkan Fahri } \\
\text { untuk ke mesjid bersama } \\
\text { - Fahri dan Paman Hulusi saling } \\
\text { mengingatkan sholat } \\
\text { - Syaikh Utsman meminta Fahri } \\
\text { untuk mengajarkan ilmunya }\end{array}$ & $\begin{array}{l}\text { - bi Al Lisan } \\
\text { - bi Al Lisan } \\
\text { - bi Al Lisan }\end{array}$ \\
\hline & Bab 24 & $\begin{array}{l}\text { - Fahri menasihati Paman Hulusi } \\
\text { untuk menolong Sabina }\end{array}$ & - bi Al Lisan \\
\hline & Bab 25 & $\begin{array}{l}\text { - Fahri mengajar Al-Qur'an dan } \\
\text { qira'ah sab'ah } \\
\text { - Fahri berdiskusi dengan Profesor } \\
\text { Charlotte tentang Islam }\end{array}$ & $\begin{array}{l}\text { - bi Al Lisan } \\
\text { - bi Al Lisan }\end{array}$ \\
\hline $\begin{array}{l}\text { Klimaks } \\
\text { (konflik } \\
\text { memuncak) }\end{array}$ & Bab 26 & $\begin{array}{l}\text { - Fahri memberitahu Sabina bahwa } \\
\text { sumpah boleh dibatalkan jika tidak } \\
\text { pada tempatnya } \\
\text { - Fahri menasihati Paman Hulusi } \\
\text { unruk ikhlas dan ikut mencari } \\
\text { Sabina }\end{array}$ & - bi Al Lisan \\
\hline & Bab 27 & $\begin{array}{l}\text { - Fahri bergegas membawa Nenek } \\
\text { Catarina ke rumah sakit }\end{array}$ & - bi Al Hal \\
\hline
\end{tabular}




\begin{tabular}{|c|c|c|}
\hline & $\begin{array}{l}\text { - Fahri menjelaskan tentang puasa } \\
\text { pada Nenek Catarina } \\
\text { - Fahri berdiskusi dengan pemuka } \\
\text { agama lain tentang amalek }\end{array}$ & $\begin{array}{l}\text { - bi Al Lisan } \\
\text { - bi Al Lisan }\end{array}$ \\
\hline Bab 28 & $\begin{array}{l}\text { - Fahri meminta Jason untuk } \\
\text { memikirkan kembali keputusannya } \\
\text { - Fahri menjelaskan pada Paman } \\
\text { Hulusi dan Misbah tentang } \\
\text { anjurannya pada Jason } \\
\text { - Fahri mengajarkan qira'ah sab'ah }\end{array}$ & $\begin{array}{l}\text { - bi Al Lisan } \\
\text { - bi Al Lisan } \\
\text { - bi Al LIsan }\end{array}$ \\
\hline Bab 29 & $\begin{array}{l}\text { - Fahri lebih memilih untuk } \\
\text { menemui Nenek Catarina } \\
\text { dibandingkan jalan-jalan ke Oxford } \\
\text { - Fahri memberikan jawaban bijak } \\
\text { kepada Nenek Catarina } \\
\text { - Ibu Fahri menasihati Fahri untuk } \\
\text { menikah lagi }\end{array}$ & $\begin{array}{l}\text { - bi Al Lisan } \\
\text { - bi Al Lisan }\end{array}$ \\
\hline Bab 30 & $\begin{array}{l}\text { - Fahri bersabar atas perlakuan Keira } \\
\text { padanya } \\
\text { - Fahri memberikan penjelasan } \\
\text { kepada Paman Hulusi tentang } \\
\text { pilihan-pilihan yang Fahri ambil } \\
\text { dalam mengatasi masalah } \\
\text { - Fahri menasihati Jason untuk } \\
\text { pulang ke rumah } \\
\text { - Fahri mengajak Misbah dan Paman } \\
\text { Hulusi untuk sholat berjamaah } \\
\text { - Fahri menyerahkan kembali uang } \\
\text { ke Nyonya Janet untuk } \\
\text { dimanfaatkan membuat lembaga } \\
\text { sosial } \\
\text { - Fahri menyumbangkan uang dua } \\
\text { kali lipat lebih banyak untuk }\end{array}$ & $\begin{array}{l}\text { - bi Al Lisan } \\
\text { - bi Al Lisan } \\
\text { - bi Al Hal }\end{array}$ \\
\hline
\end{tabular}


Kurnia, Chelsy, Representasi Dakwah dalam Novel Ayat-ayat Cinta...

\begin{tabular}{|c|c|c|c|}
\hline & & keperluan mesjid & \\
\hline & Bab 31 & $\begin{array}{l}\text { - Fahri mengingatkan } \\
\text { melakukan demo yang tidak } \\
\text { anarkis }\end{array}$ & - bi Al Lisan \\
\hline & Bab 32 & $\begin{array}{l}\text { - Fahri mengedit tulisan seorang } \\
\text { profesor tentang sejarah Al-Qur'an } \\
\text { - Fahri tetap sabar walaupun Keira } \\
\text { menuduhnya } \\
\text { - Fahri mengisi pengajian di } \\
\text { Manchester } \\
\text { - Ustad Jalal menasihati Fahri untuk } \\
\text { menikah lagi }\end{array}$ & $\begin{array}{l}\text { - bi Al Qalam } \\
\text { - bi Al Hal } \\
\text { - bi Al Lisan } \\
\text { - bi Al Lisan }\end{array}$ \\
\hline & Bab 34 & $\begin{array}{l}\text { - Fahri memberi saran untuk masalah } \\
\text { yang terjadi antara Keira dan } \\
\text { Madam Varenka }\end{array}$ & - bi Al Lisan \\
\hline & Bab 35 & $\begin{array}{l}\text { - Fahri tampil menjadi salah satu } \\
\text { pembicara di debat Oxford Union }\end{array}$ & - bi Al Lisan \\
\hline & Bab 37 & $\begin{array}{l}\text { - Fahri mengajarkan tahsin pada } \\
\text { istrinya } \\
\text { - Sabina memberikan nasihat kepada } \\
\text { Hulya }\end{array}$ & $\begin{array}{l}\text { - bi Al Lisan } \\
\text { - bi Al Lisan }\end{array}$ \\
\hline Akhir cerita & Bab 38 & $\begin{array}{l}\text { - Fahri menjadi narasumber di } \\
\text { berbagai acara } \\
\text { - Fahri banyak menulis artikel dan } \\
\text { diterbitkan di media }\end{array}$ & $\begin{array}{l}\text { - bi Al Lisan } \\
\text { - bi Al Qalam }\end{array}$ \\
\hline & Bab 39 & $\begin{array}{l}\text { - Fahri membuka identitasnya } \\
\text { sebagai penolong Keira }\end{array}$ & - bi Al Hal \\
\hline & Bab 40 & $\begin{array}{l}\text { - Jason tidak ragu mengungkapkan } \\
\text { dirinya sebagai seorang Muslim di } \\
\text { Inggris Raya } \\
\text { - Fahri mengajarkan qira'ah sab'ah } \\
\text { - Fahri menjadi pemberi kajian di } \\
\text { acara TV }\end{array}$ & $\begin{array}{l}\text { - bi Al Lisan } \\
\text { - bi Al Lisan }\end{array}$ \\
\hline
\end{tabular}




\begin{tabular}{|l|l|l|l|}
\hline & $\begin{array}{l}\text { - Fahri mengisi pengajian } \\
\text { - Hulya menolong Keira yang } \\
\text { dilecehkan }\end{array}$ & $\begin{array}{l}\text { - bi Al Lisan } \\
\end{array}$ \\
\cline { 2 - 5 } & Bab 41 & $\begin{array}{l}\text { - Para guru memberikan pendapat } \\
\text { untuk masalah Keira }\end{array}$ & - bi Al Lisan \\
\cline { 2 - 5 } & Bab 42 & $\begin{array}{l}\text { Fahri memperingatkan Sabina } \\
\text { tentang dosa menyakiti suami }\end{array}$ & - bi Al Lisan \\
\hline
\end{tabular}

Berdasarkan penelitian, didapatkan hasil bahwa ketiga macam dakwah ini direpresentasikan pada setiap bagian alur cerita novel Ayat-Ayat Cinta 2. Hampir di setiap bab dalam novel Ayat-Ayat Cinta 2 merepresentasikan dakwah kecuali bab 21, 33, dan 36. Dakwah bi Al-Lisan ditunjukkan pada 11 bagian cerita di alur awal, 12 bagian cerita di alur gangguan, 20 bagian cerita di alur komplikasi, 15 bagian cerita di alur klimaks, dan 7 bagian cerita di alur akhir.Dakwah bi AL-Hal ditunjukkan pada 5 bagian cerita di alur awal, 8 bagian cerita di alur gangguan, 12 bagian cerita di alur komplikasi, 8 bagian cerita di alur klimaks, dan 2 bagian cerita di alur akhir. Dakwah bi Al-Qalam ditunjukkan pada 1 bagian cerita di alur awal, 1 bagian di alur komplikasi, 1 bagian cerita di alur klimaks, dan 1 bagian cerita di alur akhir.

\section{Analisis Naratif Algirdas Greimas pada Tokoh}

Algirdas Greimas mengembangkan lebih lanjut analisis Propp tentang tokoh dalam cerita. Analisis Greimas ini digambarkan dalam sebuah model atau skema yang disebut skema aktan untuk melihat interaksi antara satu karakter/tokoh dengan yang lainnya. Dari hasil penelitian identifikasi masalah yang pertama, didapatkan banyak sekali bagian cerita yang merepresentasikan dakwah dalam novel Ayat-Ayat Cinta 2. Pada setiap bagian cerita ada tokoh yang berperan sebagai penyampai dakwah $\left(d a^{\prime} i\right)$ dan penerima atau sasaran dakwah (mad'u). Dalam menguraikan analisis berdasarkan tokoh ini, peneliti memasukkan beberapa bagian cerita ke dalam skema aktan. Peneliti memilih berdasarkan kategori dakwahnya, subjek yang melakukan dakwah, pengirim, pendukung, serta penerima dakwah tersebut. Berdasarkan skema aktan, yang dikategorikan sebagai 
penyampai dakwah adalah Muslim yang menempati fungsi sebagai subjek, pengirim dan pendukung, sedangkan yang dikategorikan sebagai sasaran dakwah adalah siapa saja yang menempati fungsi penerima.

Didapatkan hasil bahwa tokoh yang melakukan dakwah dalam novel ini diantaranya :

Tabel 2. Tokoh Pelaku Dakwah

\begin{tabular}{|l|l|}
\hline \multicolumn{1}{|c|}{ Tokoh } & \multicolumn{1}{c|}{ Keterangan } \\
\hline Fahri & $\begin{array}{l}\text { Tstri Fahri, sepupu } \\
\text { Aisha }\end{array}$ \\
\hline Hulya & Asisten Fahri \\
\hline Paman Hulusi & $\begin{array}{l}\text { Rekan Fahri saat di } \\
\text { Jalal }\end{array}$ \\
\hline Sabina & $\begin{array}{l}\text { Pengemis, } \\
\text { pembantu Fahri }\end{array}$ \\
\hline $\begin{array}{l}\text { Taher Khan dan } \\
\text { Heba }\end{array}$ & \begin{tabular}{l} 
Rekan Fahri \\
\hline $\begin{array}{l}\text { Mosa } \\
\text { Abdelkerim }\end{array}$
\end{tabular} \\
\hline Syaikh Utsman & Guryawan Fahri \\
\hline Jason & Tetangga Fahri \\
\hline Ibu Fahri & \\
\hline
\end{tabular}

Berdasarkan hasil penelitian, diketahui bahwa sebagian besar dakwah yang ditunjukkan di dalam novel ini dilakukan oleh Fahri. Fahri menempati 35 fungsi subjek, 1 fungsi pengirim, dan 1 fungsi pendukung. Selanjutnya Paman Hulusi menempati 2 fungsi subjek dan 6 fungsi pendukung. Misbah menempati 3 fungsi subjek dan 1 fungsi pendukung. Heba menempati 1 fungsi pengirim dan 2 fungsi subjek. Syaikh Utsman menempati 2 fungsi subjek. Sabina menempati 2 fungsi subjek dan 1 fungsi pendukung. Paman Eqbal, Ibu Fahri, Ustad Jalal, Syaikh 
Yunus, Tuan Taher, Jason dan Hulya masing-masing menempati 1 fungsi subjek. Lalu Brother Mosa dan jamaah masjid masing-masing menempati 1 fungsi pendukung. Diketahui juga bahwa dakwah tidak terbatas pada suatu latar belakang atau status tertentu. Dakwah bisa dilakukan oleh siapa saja. Seorang ustad, orang terpelajar, asisten rumah tangga, bahkan mualaf juga bisa melakukan dakwah. Tokoh yang melakukan dakwah ini adalah orang yang tahu dan paham tentang apa yang seharusnya dilakukan lalu mengajak orang lain untuk melakukan hal yang sama.

Dalam dakwah bi Al-Lisan, tokoh yang menjadi penyampai dakwah adalah Fahri, Heba, Misbah, Paman Hulusi, Syaikh Utsman, Paman Eqbal, Ibu Fahri, Ustad Jalal, Sabina, dan Syaikh Yunus Abdul Manan yang menempati fungsi subjek, Fahri dan seorang jamaah yang menempati fungsi pendukung, serta Fahri dan Heba yang menempati fungsi pengirim. Sedangkan tokoh yang menjadi sasaran dakwah adalah Mahasiswa, Fahri, Juu Suh, Imam masjid, Tuan Taher, Paman Hulusi, Ashley, Misbah, Nyonya Janet, orang-orang Yahudi, jamaah, Nenek Catarina, pemuka agama lain, Jason, demonstran, Madam Varenka dan Hulya. Dakwah bi Al-Lisan dilakukan kepada siapa saja mulai dari orang terdekat hingga orang-orang dari agama lain. Dalam melakukan dakwah bi Al-Lisan Fahri dan juga tokoh-tokoh lainnya menggunakan cara yang sopan, tidak menyinggung, dan juga tidak memaksa hal ini sesuai dengan ajaran yang melarang untuk melakukan kekerasan dan pemaksaan dalam beragama.

Dalam dakwah bi Al-Hal, tokoh yang menjadi penyampai dakwah adalah Fahri, Heba, Misbah, Tuan Taher, Jason dan Hulya yang menempati fungsi subjek serta Paman Hulusi, Brother Mosa, dan Sabina yang menempati fungsi pendukung. Sedangkan tokoh ysng menjadi sasaran dakwahnya adalah Jason, Misbah, Paman Hulusi, Nenek Catarina, Profesor Charlotte, Nyonya Janet, Keira, para pengemis di Edinburgh, Sabina, dan masyarakat. Dalam cerita ini sebagian besar dakwah bi Al-Hal dilakukan kepada orang-orang non-Muslim. Dalam melakukan dakwah ini diperlukan sikap dan perilaku yang sangat baik dan konsisten. Fahri sebagai tokoh utama dan pelaku sebagian besar dakwah dalam cerita ini merupakan seseorang yang sangat taat beragama, sabar dan juga bijak. 
Dakwah bi Al-Hal dalam novel ini sebagian besar bertujuan untuk menunjukkan Islam yang rahmatan lil 'alamin dan juga menjaga citra Islam agar tidak buruk. Dalam cerita ini Fahri terus menerus bersikap sabar dan penolong sehingga para sasaran dakwahnya mulai menyadari bahwa Islam itu sama sekali tidak buruk dan mulai bersikap positif terhadap Islam. Selain kepada non-Muslim ada juga dakwah bi Al-Hal yang dilakukan kepada sesama Muslim seperti Fahri yang membantu menciptakan ahli Ekonomi Islam dengan membiayai Misbah dan juga Fahri berserta orang muslim lainnya yang membuat rencana untuk membantu para dhuafa dan homeless Muslim demi menjaga citra Islam

Dalam dakwah bi Al-Qalam dalam novel ini, tokoh yang meyampaikan dakwahnya hanya Fahri, dan yang menjadi sasarannya adalah para pembaca yang membaca hasil postdoc-nya dan pembaca JAIS. Dalam melakukan riset postdocnya, Fahri memilih untuk mengkaji ulang 'mutiara terpendam' atau bahasanbahasan dari para ulama. Hasil risetnya ini kemudian akan diterbitkan dan dapat dibaca serta dimanfaatkan oleh jutaan umat manusia. Melalui tulisannya inilah Fahri melakukan dakwah. Selain risetnya, Fahri juga berkolaborasi dengan seorang mahasiswanya untuk menulis artikel yang kemudian diterbitkan di Journal of Arabic \& Islamic Studies (JAIS). Mahasiswa yag menulis artikel bersama Fahri ini bukan seorang Muslim sehingga yang terhitung melakukan dakwah pada bagian cerita ini hanya Fahri.

\section{Unsur Ekstrinsik Pengarang}

Unsur ekstrinsik adalah unsur yang berada di luar karya fiksi yang memengaruhi lahirnya karya namun tidak menjadi bagian di dalam karya fiksi itu sendiri.Unsur-unsur yang dimaksud antara lain adalah keadaan subjektivitas individu pengarang yang memiliki sikap, keyakinan, dan pandangan hidup. Atau pendek kata bisa disebut biografi pengarang, psikologi pengarang atau pembaca, bisa juga berupa nilai-nilai dari luar atau yang ada di masyarakat seperti nilai ekonomi, politik, sosial, budaya dan lain sebagainya, serta pandangan hidup suatu bangsa, berbagai karya seni yang lain, dan sebagainya. 
Habiburrahaman El Shirazy atau yang akrab disapa Kang Abik adalah seorang sastrawan yang konsisten berkarya dengan genre Islami. Sejak masa sekolah menengah pertama, Kang Abik sudah bersekolah di sekolah Islam, tepatnya di sebuah MTs di Mranggen sambil belajar kitab kuning di sebuah pondok. Setelahnya beliau melanjutkan sekolah di Madrasah Aliyah Program Khusus di Surakarta, hingga akhirnya berkuliah di Mesir. Latar belakang pendidikan Kang Abik ini merupakan salah satu yang membuatnya memahami ajaran-ajaran Islam dengan baik sehingga ilmu tersebut bisa beliau curahkan ke dalam novel-novelnya termasuk salah satunya novel Ayat-Ayat Cinta 2 ini.

Habiburrahman El Shirazy mengatakan bahwa pengalamannya melakukan safari dakwah di negara-negara maju (Amerika 3 kali, Eropa Barat seperti Jerman dan Belanda 2 kali, Inggris 1 kali, dan Australia 1 kali) adalah inspirasi utama dalam penulisan novel Ayat-Ayat Cinta 2 ini. Sudah bukan hal asing lagi untuk diketahui bahwa di negara-negara maju masyarakatnya banyak yang mengidap Islamofobia. Mereka takut dan tidak suka pada agama Islam dan juga penganutnya karena banyak media-media yang memberitakan hal yang tidak benar tentang Islam. Pengalaman Kang Abik selama berdakwah di negara-negara ini membuatnya melihat lebih dekat fenomena Islamofobiaini. Berdasarkan pengetahuannya tentang agama Islam sebagai agama rahmatan lil 'alamin, Kang Abik menunjukkan contoh cara bagaimana Muslim sebaiknya menyikapiIslamofobiaini. Menghadapi orang yang anti Islam dengan mendakwahinya secara langsung dengan memberitahukan kebenaran melalui lisan merupakan hal yang kurang tepat untuk dilakukan. Karena itu pertama-tama sangat perlu untuk menampilkan sisi Islam yang positif melalui cara umatnya bersikap dan berperilaku, seperti yang dicontohkan Kang Abik dalam sosok Fahri.

Sosok Fahri digambarkan sebagai sosok sempurna yang taat pada agamanya dan ber-akhlaqul karimah. Fahri ingin apapun yang ia lakukan dapat memancarkan cahaya keindahan Islam sebagai agama yang membawa rahmat bagi seluruh alam. Sikap Fahri tidak sia-sia, terbukti bahwa dengan akhlak-akhlak baiknya terhadap siapapun Fahri mampu mengubah pikiran dan tanggapan orang di sekitarnya tentang Islam. Dalam menciptakan tokoh Fahri yang hebat dan 
sempurna, Habiburrahman El Shirazy berharap bisa memotivasi umat Islam untuk berbuat seperti Fahri. Kang Abik membuat sosok Fahri sebagai pengajar di Universitas terkenal juga karena ia terinsipirasi dari orang-orang kenalannya yang menjadi Profesor di luar negeri.

Selain berdasarkan pengetahuannya, cerita-cerita yang ditulis Habiburrahman El Shirazy juga berdasarkan pengalamannya. Menurut pengakuannya pada acara bedah novel Ayat-Ayat Cinta 2, Kang Abik mengetahui bahwa memang seperti itulah umat Muslim berdakwah di barat sana. Cerita tentang kebaikan Fahri kepada Nenek Catarina terinspirasi dari cerita orang Indonesia yang bertetangga dengan seorang Nenek asal Amerika. Mereka membantu memotongkan rumput nenek di halaman rumah nenek itu karena merasa kasihan nenek itu tinggal sendirian. Mereka juga pernah mengantarkan nenek itu ke gereja karena jalanan bersalju yang susah untuk ditempuh. Kang Abik juga terinspirasi dari gerakan para Muslim di New Castle saat musim dingin. Pada musim dingin mereka biasanya mengetuk pintu-pintu rumah orang tua dan menanyakan apakah mereka membutuhkan sesuatu misalnya ada barang yang mereka butuhkan tapi susah mereka dapatkan karena sangat dingin.

Habiburrahman El Shirazy berharap dengan adanya pesan yang ia sampaikan lewat novel Ayat-Ayat Cinta 2, umat Islam akan jadi lebih mencintai Islam, semakin cinta Allah dan Rasul-Nya, serta semakin dewasa dan cerdas dalam berdakwah. Bagi umat non muslim, beliau berharap mereka punya gambaran keindahan ajaran Islam, sehingga tidak perlu phobia pada Islam dan Muslim. Berdasarkan pernyataan Kang Abik dalam sebuah acara bedah novel, umat Islam Indonesia adalah bagian dari umat Islam dunia dan merupakan populasi terbesar. Kalau umat Islam Indonesia menjalankan Islam dengan baik, dengan santun, dan rahmatan lil 'alamin, maka masa depan Islam akan cerah. 


\section{SIMPULAN}

Sebagian besar alur awal, tengah, hingga akhir cerita dalam novel ini menunjukkan adanya perilaku dakwah. Dakwah yang dilakukan diantaranya dakwah bi Al-Lisan dengan perilaku memberi nasihat, mengisi kajian, berdiskusi dan juga upaya memperbaiki pandangan-pandangan yang salah tentang Islam. Dakwah bi Al-Hal dengan menunjukkan sikap dan perbuatan yang baik (akhlaqul karimah) sehingga mengubah pandangan orang non-Muslim terhadap Islam sertamembantu saudara Muslim yang kurang mampu sehingga mereka tidak melakukan perbuatan buruk yang merusak citra Islam. Dakwah bi Al-Qalam dengan menulis riset dan artikel keislaman.

Dakwah dalam novel ini dilakukan oleh Fahri. Fahri melakukan semua jenis dakwah. Tokoh lain yang menjadi penyampai dakwah adalah Paman Hulusi, Misbah, Heba, dan Sabina melakukan dakwah bi Al-Lisan dan dakwah bi Al-Hal. Syaikh Utsman, Paman Eqbal, Ibu Fahri, Ustad Jalal, Syaikh Yunus Abdul Manan, dan seorang jamaah melakukan dakwah bi Al-Lisan. Tuan Taher, Jason, Hulya, dan Brother Mosa melakukan dakwah bi Al- Hal. Mereka adalah tokoh yang beragama Islam dan menempati posisi sebagai subjek, pengirim, dan pendukung dalam skema aktan. Dakwah bi Al-Lisan dilakukan kepada siapa saja mulai dari orang terdekat hingga orang-orang dari agama lain. Sebagian besar dakwah bi Al-Hal dilakukan kepada orang-orang non-Muslim. Dakwah bi AlQalam ditujukan kepada para pembaca karya.Unsur ekstrinsiknya yaitu, biografi atau tepatnya latar belakang pendidikan, pengalaman pribadi, serta keadaan sosial yang dilihat dan dialami pengarang.

\section{DAFTAR PUSTAKA}

Alhikmahtv. 2017. Bedah Novel Ayat-Ayat Cinta 2 Bersama Habiburrahman El Shirazy IBF 2016. Youtube.com, [online]. 14 Mei. dalam https://www.youtube.com/watch?v=NO_JGiDQK0w.

Amin, Samsul Munir., 2013. Ilmu Dakwah. Jakarta: Amzah.

Ariyani, Isma. 2014. Representasi Nilai Siri' pada Sosok Zainuddin dalam Novel Tenggelamnya Kapal Van Der Wijck (Analisis Framing Novel). Skripsi Sarjana. Makassar: Jurusan Ilmu Komunikasi Fakultas Ilmu Sosial dan Ilmu Politik Universitas Hasanuddin.

Branston, Gill dan Roy Stafford., 2003. The Media Student's Book. London: Routledge. 
Danesi,Marcel., 2010.Pengantar Memahami Semiotika Media. Yogyakarta: Jalasutra.

Eriyanto., 2013. Analisis Naratif Dasar-Dasar dan Penerapannya dalam Analisis Teks Berita Media. Jakarta: Prenada Media Group.

Hartley, John., 2010.Communication, Cultural, and Media Studies: Konsep. Kunci.Yogyakarta: Penerbit Jalasutra.

Muftisany, Hafidz., 2015. Ayat-Ayat Cinta 2 Dibedah di Amerika Serikat. Republika.co.id. [internet]. 29 Desember. dalam http://www.republika.co.id/berita/koran/khazanahkoran/15/12/29/o03vcf15-ayatayat-cinta-2-dibedah-di-amerika-serikat [diakses 17 Desember 2017].

Nurgiyantoro, Burhan., 2013. Teori Pengkajian Fiksi. Yogyakarta : Gadjah Mada University Press.

Putra, Erik Purnama., 2015. Umum. Sastra Islami Sudah Menjadi Mainstream. Nasional.republika.co.id, [internet]. 13 Maret. Dalam http://nasional.republika.co.id/berita/nasional/umum/15/03/12/nl3k5asastra-islami-sudah-menjadi-mainstream [diakses 16 Desember 2017] Teguh, Antero. 2015. Bedah Buku Ayat-Ayat Cinta 2 (Kang Abik). Youtube.com, [online]. 26 Desember. dalam https://www.youtube.com/watch?v=FqKCizKTorU.

Vacliuca, Queentha. 2016. Representasi Gaya Hidup Mahasiswa dalam Novel Good Memories Karya Lia Indra Andriana. Skripsi Sarjana. Pekanbaru: Jurusan Ilmu Komunikasi Fakultas Ilmu Sosial dan Ilmu Politik Universitas Riau. 